\title{
Ancient seawater compositions recorded in nanoscale fluid inclusions in pyrite?
}

S. D. TAYLOR, ${ }^{1 *}$ D. E. PEREA, ${ }^{1}$ L. KOVARIK, ${ }^{1}$
J. B. ClifF, ${ }^{1}$ D. D. GREGORY, ${ }^{2}$ T. W. LyONS ${ }^{3}$

${ }^{1}$ Environmental Molecular Sciences Laboratory, Pacific Northwest National Laboratory, Richland, WA 99354,

USA (*Corresponding author: sandra.taylor@pnnl.gov)

${ }^{2}$ University of Toronto, Toronto, ON M5S 3B1, Canada

${ }^{3}$ University of California, Riverside, CA 92521, USA

New insight into the geochemistry of ancient environments can be gained through structural and chemical analyses of nanometer-scale features within minerals. Here, we present recent developments using atom probe tomography (APT), enabling direct visualization of nanoscale fluid inclusions trapped within pyrite $\left(\mathrm{FeS}_{2}\right)$ and chemical characterization of remnant seawater. Framboids consisting of pyrite nanocrystals ( 200-400 $\mathrm{nm}$ large) were sampled from the Middle Devonian Leicester Pyrite Member (New York). Scanning transmission electron microsopy shows low density regions distributed within the pyrite consistent with nanoscale pores $(<4 \mathrm{~nm}$ in size). Interestingly, APT compositional mapping shows the nanopores are filled with water. 3D visualization reveals the water-filled pores are oblate to spheroidal clusters containing $\mathrm{Na}, \mathrm{K}, \mathrm{Mg}$, and $\mathrm{Ca}$ alkali ions $(<0.2$ ionic\%). These findings collectively indicate recovery of nanoscale fluid inclusions within the pyrite matrix.

The inclusions appear to preserve the elemental signature of the water column in which the framboids formed. $\mathrm{Mg}: \mathrm{Ca}$ ratios in the fluid inclusions were quantified with APT as this is commonly used to infer oscillations in seawater chemistry over geologic time based on $\mathrm{CaCO}_{3}$-polymorph formation; i.e., periods of lower seawater temperatures and calcite formation are nominally marked by $\mathrm{Mg}: \mathrm{Ca} \leq 2.0$ while $\mathrm{Mg}: \mathrm{Ca}>2.0$ indicates higher temperature, aragonite-dominant environments. $\mathrm{Mg}: \mathrm{Ca}$ ratios within the pyrite were generally measured to be within $0.4 \pm 0.1$ to $1.4 \pm 0.3$ - consistent with calcite-dominated seawater conditions existing in the Middle Devonian. Some deviations in $\mathrm{Mg}: \mathrm{Ca}$ were found in specimens devoid of inclusions (i.e., $4.5 \pm 1.8$ and 10.6 \pm 2.6 ), correlating to preferential incorporation of $\mathrm{Mg}$ into the pyrite lattice over $\mathrm{Ca}$. This study demonstrates the potential of a novel approach to reconstruct paleoenvironmental conditions from coupled elemental and structural analyses of nanoscale fluid inclusions. Further exploration of nanoscale features within minerals using this unique approach can be used to provide unprecedented insight across various geological processes including crystal growth and trace element cycling. 